\title{
Femoral artery cannulation for thoracic aortic surgery: Safe under transesophageal echocardiographic control
}

\author{
Bassem Ayyash, MD, Maryann Tranquilli, RN, and John A. Elefteriades, MD
}

\begin{abstract}
Objective: Choice of cannulation site (femoral, axillary) for cardiopulmonary bypass for thoracic aortic surgery is controversial. We review a single-center consecutive experience with femoral cannulation in the era of transesophageal echocardiography (TEE).
\end{abstract}

\begin{abstract}
Methods: Femoral artery cannulation is our preference for both aneurysms and dissections. If intraoperative TEE (or preoperative computed tomography) shows mobile atheroma, we avoid femoral cannulation and use the right axillary artery. Charts were reviewed to detect any cannulation- or perfusion-related complications.

Results: Eight hundred eighty patients underwent cannulation for cardiopulmonary bypass for thoracic aortic surgery: 767 femoral $(87 \%)$ and 113 other (13\%, 87 aortic, 22 axillary, 4 innominate). Among the femoral cases, $673(87.7 \%)$ were elective and $94(12.2 \%)$ urgent or emergency. Hospital survival was 723 of 767 (94\%): 654 of $673(97 \%)$ for elective cases and 69 of $94(73 \%)$ for urgent or emergency cases. Survivals were 549 of $572(95 \%)$ for ascending and arch, 91 of 97 (93\%) for descending, and 83 of $98(84 \%)$ for thoracoabdominal. Stroke (fixed neurologic deficit) occurred in 14 of 767 cases (1.8\%): 9 ascending or arch and 5 descending or thoracoabdominal. There were 5 paraplegias in the descending or thoracoabdominal group. There was 1 instance of intraoperative descending dissection (well tolerated), no arterial ruptures, and 6 instances $(0.7 \%)$ of local femoral arterial narrowing requiring surgical correction (patch graft). One patient $(0.1 \%)$ had postoperative ischemia of the cannulated limb, and 25 patients (3.2\%) had local wound problems (infection 21, seroma 4) treated conservatively.
\end{abstract}

Conclusions: This large experience in the TEE era strongly supports femoral cannulation for aortic surgery, with good survival, low stroke rate, minimal perfusion-related rupture or dissection, and minimal limb ischemia. If intraoperative TEE shows mobile atheroma, axillary cannulation is preferred. (J Thorac Cardiovasc Surg 2011;142:1478-81)

The use of femoral artery cannulation in cardiopulmonary bypass has been controversial since its introduction in the 1950s. ${ }^{1,2}$ Early complications associated with femoral cannulation for cardiac surgery, mainly related to arterial dissection, were reported in the 1960s. This method was soon replaced by direct cannulation of the distal ascending aorta in the main surgical field. Use of the femoral artery remained as an alternative, especially in the case of disease of the thoracic aorta. Nevertheless, complications related to retrograde perfusion were reported with femoral cannulation, which stimulated investigation of alternative cannulation sites and ultimately led to the popularity of the axillary artery for perfusion in thoracic aortic surgery. Although certain institutions continue to use the femoral artery for thoracic aortic surgery, many surgeons are skeptical regarding the safety of femoral cannulation in this application.

From the Section of Cardiac Surgery, Yale University School of Medicine, New Haven, Conn.

Disclosures: Authors have nothing to disclose with regard to commercial support.

Received for publication Dec 11, 2010; revisions received Feb 23, 2011; accepted for publication April 6, 2011.

Address for reprints: John A. Elefteriades, MD, Cardiac Surgery, Boardman 2, 333

Cedar St, New Haven, CT 06510 (E-mail: john.elefteriades@yale.edu).

0022-5223/\$36.00

Copyright (C) 2011 by The American Association for Thoracic Surgery

doi:10.1016/j.jtcvs.2011.04.005
We wished to investigate this topic in light of our clinical experience, because femoral cannulation remains the method of choice at our institution. We reviewed 880 cases of thoracic aortic surgery, which included 767 cases of femoral cannulation. The aim of this study was to use this large clinical experience to determine the safety of femoral cannulation in thoracic aortic surgery.

\section{MATERIALS AND METHODS}

Medical records, computer records, operative notes, and discharge summaries were reviewed for all patients who underwent thoracic aortic surgery at our institution, including ascending and arch, descending, and thoracoabdominal aortic procedures, between the years 1999 and 2010. Records were reviewed for cannulation site, operative procedure, and clinical outcome. Specific attention was paid to complications associated with femoral cannulation. We searched specifically for intraoperative local arterial injuries (rupture or dissection), postoperative limb ischemia, wound complications, strokes, malperfusion phenomena, paraplegia and deathcomplications that could potentially be related to the site of cannulation and to retrograde perfusion.

This study was performed under the human investigation committee protocol for clinical research with the database of the Aortic Institute at Yale-New Haven.

In terms of brain preservation, straight deep hypothermic circulatory arrest was used, without antegrade or retrograde cerebral perfusion. Cooling was performed to the level at which bladder temperature reached $18^{\circ} \mathrm{C}$. The patient's head was packed with ice. No cerebral oximetry or electroencephalographic monitoring was used. Rewarming was performed slowly (over 


\section{Abbreviation and Acronym}

$\mathrm{TEE}=$ transesophageal echocardiography

about 1 hour) and taken to $34^{\circ} \mathrm{C}$ to $35^{\circ} \mathrm{C}$; further warming was completed in the intensive care unit.

\section{RESULTS}

Eight hundred eighty patients (536 male and 344 female) were found to have undergone cannulation for cardiopulmonary bypass for thoracic aortic surgery. Seven hundred sixty-seven of these cannulations $(87 \%)$ were performed in the femoral artery, 87 were direct aortic, 22 were in the axillary artery, and 4 were in the innominate artery. Femoral cannulation was our preferred approach, and nonfemoral cannulations were chosen for various reasons. Intraoperative transesophageal echocardiography (TEE) was used routinely in all types of aortic operations. If intraoperative TEE demonstrated mobile atheroma-suggesting that embolization might occur with retrograde perfusion through the femoral artery-a site other than the femoral artery was chosen for cannulation. See Table 1 for clinical information on these cases in whom nonfemoral cannulation was chosen. Also, if the preoperative computed tomographic scan demonstrated severe arteriosclerosis of the descending or abdominal aorta, with potentially mobile forms, femoral cannulation was avoided. Other reasons for nonfemoral cannulation included peripheral vascular disease (with decreased femoral or pedal pulses), femoral artery calcification or friability, and reluctance to access the femoral artery because of the patient's extreme obesity.

A Bard femoral cannula (C. R. Bard, Inc, Murray Hill, $\mathrm{NJ})$ was used routinely for femoral cannulation until 2007. At that time, the Seldinger-guided FemFlex and FemFlex II cannulas (Edwards Lifesciences LLC, Irvine, Calif) became our routine choice for femoral artery cannulation.

Among the 767 femorally cannulated patients, 673 procedures $(87.7 \%)$ were elective and $94(12.2 \%)$ were performed on an urgent or emergency basis. Hospital survival was 723 of 767 (94\%) overall: 654 of 673 (97\%) for elective cases and 69 of $94(73 \%)$ for urgent or emergency cases.

Surgical procedures included 572 operations $(74.5 \%)$ for the ascending aorta and arch, 97 operations $(12.6 \%)$ for the descending aorta, and 98 operations $(12.6 \%)$ for the thoracoabdominal aorta. Survivals in all cases (both elective and urgent or emergency) were 549 of $572(95 \%)$ for ascending and arch procedures, 91 of 97 (93\%) for descending procedures, and 83 of $98(84 \%)$ for thoracoabdominal procedures.

Sixty-four of the femoral cannulations were done for acute ascending aortic dissection; the hospital survival of these patients was 48 of $64(75 \%)$. Of the 16 acute ascending dissection deaths, 2 occurred in patients who were not femorally cannulated ( 1 axillary, 1 direct aortic). Causes of death in the 14 femorally cannulated acute ascending aortic dissection patients included failure to wean from cardiopulmonary bypass or pump failure $(\mathrm{n}=4)$, bleeding $(\mathrm{n}=4)$, respiratory failure $(\mathrm{n}=3)$, sepsis $(\mathrm{n}=1)$, arrhythmia or bradycardia $(\mathrm{n}=1)$, and cerebrovascular accident $(\mathrm{n}=1)$. In none of these cases was femoral cannulation or malperfusion the suspected cause of death, either at the time or in retrospective review.

There was 1 instance of intraoperative dissection of the descending aorta during an ascending aortic replacement in an elderly female patient perfused from the femoral artery. This required no treatment other than moving the cannula to the ascending aorta, and the descending dissection has remained stable during the ensuing 4 years. There were no aortic or iliac ruptures or malperfusion phenomena.

Stroke (fixed neurologic deficit) occurred in 14 of 767 $(1.8 \%)$ cases, with 9 among these ascending or arch operations and the remaining 5 descending or thoracoabdominal operations.

There were 5 paraplegia cases in the descending or thoracoabdominal group $(2.6 \%)$.

No cases of intraoperative arterial rupture or dissection related to perfusion were reported, and there were no malperfusion phenomena detected. Local femoral arterial narrowing, requiring surgical correction with patch graft (5 vein patch grafts and 1 pericardial) at the completion of the original surgical procedure, occurred in 6 cases.

A single patient had postoperative limb ischemia and compartment syndrome, requiring fasciotomy. He died later in the intensive care unit of multiple organ failure.

Postoperative local wound complications were observed in 25 patients $(3.2 \%)$. There were 21 infections and 4 seromas. Twenty-four patients had local wound problems on the first office visit after discharge, and 1 patient had wound infection develop on the day of discharge. All 25 cases were managed successfully with topical antiseptics (quarterstrength Dakin's solution).

\section{DISCUSSION}

After its introduction by Lillehei and Cardozo ${ }^{1}$ in 1959 , femoral cannulation acquired a checkered reputation. Early authors reported complications related to arterial injuries, such as dissection and retroperitoneal rupture with hematoma. ${ }^{2-5}$ Aortic cannulation was introduced between the years 1959 and $1963 .^{2}$ Debate regarding the optimal cannulation site, especially for aortic surgery, has continued into the past decade.${ }^{6,7}$ Not only vessel-related injuries but especially neurocognitive outcomes have been a main concern., Axillary artery cannulation, suggested by many authors as an alternative site for cannulation, has becoming increasingly popular after reports of lessened neurologic 
TABLE 1. Cases in which axillary, subclavian, or innominate cannulation was used

\begin{tabular}{|c|c|c|c|c|c|}
\hline Case & Sex & Age (y) & Procedure & Cannulation site & Imaging influencing cannulation site \\
\hline 1 & M & 84 & AVR, ascending, hemi & Axillary & TEE, deep ulcerated plaque in distal aortic arch \\
\hline 2 & M & 75 & Redo aortic root, CABG (dissection) & Axillary & $\begin{array}{l}\mathrm{CT} \text {, heavily diseased descending aorta after } \\
\text { dissection }\end{array}$ \\
\hline 3 & $\mathrm{~F}$ & 78 & Ascending, hemi & Axillary & \\
\hline 4 & $\mathrm{~F}$ & 44 & Ascending, hemi & Axillary & $\mathrm{CT}$, thoracoabdominal arteriosclerosis \\
\hline 5 & $\mathrm{~F}$ & 82 & AVR, ascending, arch (dissection) & Axillary & TEE, severe atheroma descending aorta \\
\hline 6 & $\mathrm{~F}$ & 84 & Ascending, hemi, CABG & Axillary & TEE, thrombus in aortic arch \\
\hline 7 & $\mathrm{~F}$ & 73 & AVR. ascending, arch & Axillary & $\begin{array}{l}\text { CT, large thoracoabdominal aortic aneurysm, } \\
\text { layers of laminated clot }\end{array}$ \\
\hline 8 & $\mathrm{~F}$ & & Arch (redo, dissection) & Axillary & CT, pseudoaneurysm in arch \\
\hline 9 & M & & Root & Axillary & TEE, much arteriosclerosis \\
\hline 10 & M & 65 & Arch (redo), CABG (stage 1 elephant trunk) & Axillary & $\begin{array}{l}\mathrm{CT} \text {, pseudoaneurysm beyond subclavian; TEE, } \\
\text { moderate descending arteriosclerosis }\end{array}$ \\
\hline 11 & M & & Arch (redo, dissection, stage 1 elephant trunk) & Axillary & TEE, mobile atheroma descending \\
\hline 12 & M & 70 & Redo (heart transplant) & Axillary & TEE, heavy arch atheroma \\
\hline 13 & $\mathrm{~F}$ & 71 & Root, hemi (dissection) & Axillary & $\mathrm{CT}$, heavy arch and descending arteriosclerosis \\
\hline 14 & M & 46 & Ascending, arch, CABG (stage 1 elephant trunk) & Axillary & $\mathrm{CT}$, thoracoabdominal aneurysm \\
\hline 15 & $\mathrm{~F}$ & 76 & Arch, descending (redo, thoracotomy) & Subclavian & $\begin{array}{l}\text { CT, distal arch and proximal descending } \\
\text { aneurysm; TEE, severe arch arteriosclerosis }\end{array}$ \\
\hline 16 & $\mathrm{~F}$ & 76 & Ascending, arch, CABG & Axillary & $\begin{array}{l}\mathrm{CT} \text {, arch aneurysm; TEE, descending } \\
\text { arteriosclerosis }\end{array}$ \\
\hline 17 & M & 49 & Arch, descending (thoracotomy, dissection) & Subclavian & CT, large amount of clot in false lumen \\
\hline 18 & $\mathrm{~F}$ & 70 & Ascending, arch & Axillary & $\mathrm{CT}$, distal arch aneurysm \\
\hline 19 & $\mathrm{~F}$ & & Ascending, hemi, axillary (dissection) & & $\mathrm{CT}$, thrombus in false lumen \\
\hline 20 & M & 57 & $\begin{array}{l}\text { Ascending, arch (redo, stage } 1 \text { of total aortic } \\
\text { replacement) }\end{array}$ & Innominate artery & $\begin{array}{l}\mathrm{CT} \text {, large amount of thrombus in } \\
\text { thoracoabdominal aneurysm }\end{array}$ \\
\hline 21 & M & 58 & Root & Innominate artery & TEE, calcified plaque at subclavian \\
\hline 22 & $\mathrm{~F}$ & 70 & AVR, ascending, arch & Innominate artery & $\mathrm{CT}$, debris in descending aorta \\
\hline 23 & M & 56 & Root & Innominate artery & $\begin{array}{l}\mathrm{CT} \text {, aortoiliac aneurysm; TEE, arch and } \\
\text { descending arteriosclerosis }\end{array}$ \\
\hline 24 & $\mathrm{~F}$ & 78 & Ascending, arch (stage I elephant trunk) & Innominate artery & $\begin{array}{l}\mathrm{CT} \text {, descending aneurysm; TEE, diffuse } \\
\text { arteriosclerosis }\end{array}$ \\
\hline 25 & M & 82 & Ascending, arch (stage I elephant trunk) & Innominate artery & $\begin{array}{l}\text { CT, massive descending aneurysm; TEE, heavy } \\
\text { descending arteriosclerosis }\end{array}$ \\
\hline
\end{tabular}

$M$, Male; $A V R$, aortic valve replacement; hemi, hemi-arch; $T E E$, intraoperative transesophageal echocardiography; $C A B G$, coronary artery bypass grafting; $C T$, computed tomography; $F$, female.

complications. ${ }^{10-12}$ Other sites, such as the innominate and carotid arteries, have also been used for cannulation..$^{13,14}$ Axillary cannulation, although usually well tolerated, has itself been associated with serious complications, including brachial plexus injury, arm ischemia, dissection, and malperfusion during cardiopulmonary bypass. ${ }^{15-18}$

In our large study, we found essentially no local vessel problems such as femoral or iliac artery rupture or dissection. There was a single case of intraoperative descending aortic dissection, but this required no specific treatment. We observed no malperfusion phenomena. Even in cases of acute ascending aortic dissection, we did not see any problems related to femoral cannulation. The stroke rates observed in our study are well within the expected range and do not suggest any adverse effect of putative retrograde embolization related to femoral artery perfusion from below. This study confirms in the overall thoracic aortic pop- ulation the earlier preliminary positive observations that we made regarding femoral cannulation for ascending aortic dissection. ${ }^{19}$ In that study, femoral cannulation produced an $83 \%$ overall survival, with only a $3.7 \%$ malperfusion event rate. In this study, we consider it very likely to be the improved imaging of the intervening abdominal and descending aortas (by TEE) that permitted us to exclude patients potentially vulnerable to retrograde embolization of mobile aortic debris. Thus in the current echocardiographic era the attractiveness of femoral cannulation may deserve reconsideration, or even a recrudescence.

In terms of study limitations, it is important to note that this was a large observational (not comparative) study on thoracic aortic surgery performed predominantly with femoral cannulation. It was not powered or intended to compare axillary and femoral cannulation techniques. It is also important to note that axillary cannulation provides an 
immediate, simple means of providing antegrade cerebral perfusion to the right side of the brain by clamping the origin of the innominate artery during deep hypothermic arrest. This direct option is not applicable with femoral perfusion. In our series, we used straight deep hypothermic circulatory arrest for brain preservation. We have published separately regarding our positive experience with this approach to cerebral protection. ${ }^{20-22}$

With specific regard to axillary cannulation, it is important to note that the literature demonstrates clearly that use of the axillary artery is far from benign. Reports note significant complications in $14 \%$ of cases (vessel dissection, inadequate forward flow or high arterial line pressures, brachial plexus injury) and the need to move the cannula to a femoral or central site in $11 \%$ of cases. ${ }^{12,16,23}$

This study of a large number of thoracic aortic operations performed under femoral cannulation supports the safety of femoral cannulation for thoracic aortic surgery under the guidance of intraoperative TEE. The low complication rates, arterial and neurologic, make femoral cannulation a suitable choice for arterial perfusion access for thoracic aortic surgery.

\section{References}

1. Lillehei CW, Cardozo RH. Use of median sternotomy with femoral artery cannulation in open cardiac surgery. Surg Gynecol Obstet. 1959;108:706-14.

2. Magner JB. Complications of aortic cannulation for open-heart surgery. Thorax. 1971;26:172-3.

3. Christian CM 2nd, Naraghi M. A complication of femoral arterial cannulation in a patient undergoing cardiopulmonary bypass. Anesthesiology. 1978;49:436-7.

4. Williams KR, Johnson J. Aortic dissection after femoral artery cannulation. Case with extracorporeal circulation. Arch Surg. 1964;89:663-5.

5. Bilgutay AM, Garamella JJ, Danyluk M, Remucal HC. Retrograde aortic dissection occurring during cardiopulmonary bypass. Successful repair and concomitant subclavian-to-coronary artery vein bypass. JAMA. 1976;236:465-8.

6. Lakew F, Pasek P, Zacher M, Diegeler A, Urbanski PP. Femoral versus aortic cannulation for surgery of chronic ascending aortic aneurysm. Ann Thorac Surg. 2005;80:84-8.
7. Tiwari KK, Murzi M, Bevilacqua S, Glauber M. Which cannulation (ascending aortic cannulation or peripheral arterial cannulation) is better for acute type A aortic dissection surgery? Interact Cardiovasc Thorac Surg. 2010;10: 797-802.

8. Shragge BW, Prior PL, Bauman HC, Lonn E, Merali F, Doris I. Neurocognitive outcomes after standard aortic versus femoral cannulation in coronary artery bypass graft surgery [abstract]. Ann Thorac Surg. 2000;70:1788.

9. Westaby S, Katsumata T, Vaccari G. Arch and descending aortic aneurysms: influence of perfusion technique on neurological outcome. Eur J Cardiothorac Surg. 1999; $15: 180-5$.

10. Gulbins H, Pritisanac A, Ennker J. Axillary versus femoral cannulation for aortic surgery: enough evidence for a general recommendation? Ann Thorac Surg. 2007;83:1219-24.

11. Hedayati N, Sherwood JT, Schomisch SJ, Carino JL, Markowitz AH. Axillary cannulation for cardiopulmonary bypass reduces cerebral microemboli. J Thorac Cardiovasc Surg. 2004;128:386-90.

12. Sabik J, Nemeh H, Lytle B, Blackstone EH, Gillinov AM, Rajeswaran J, et al. Cannulation of the axillary artery with a side graft reduces morbidity. Ann Thorac Surg. 2004;77:1315-20.

13. Ji S, Yang J, Ye X, Wang X. Brain protection by using innominate artery cannulation during aortic arch surgery. Ann Thorac Surg. 2008;86:1030-2.

14. Chiu KM, Li SJ, Lin TY, Chan CY, Chu SH. Innominate artery cannulation for aortic surgery. Asian Cardiovasc Thorac Ann. 2007;15:348-50.

15. Apostolakis EE, Baikoussis NG, Katsanos K, Karanikolas M. Postoperative periaxillary seroma following axillary artery cannulation for surgical treatment of acute type A aortic dissection. J Cardiothorac Surg. 2010;25(5):43.

16. Schachner T, Nagiller J, Zimmer A, Laufer G, Bonatti J. Technical problems and complications of axillary artery cannulation. Eur J Cardiothorac Surg. 2005;27:634-7.

17. Orihashi K, Sueda T, Okada K, Takahashi S. Compressed true lumen in the innominate artery: a pitfall of right axillary arterial perfusion in acute aortic dissection. J Thorac Cardiovasc Surg. 2009; 137:242-3.

18. Rescigno G, Aratari C, Matteucci M. Axillary artery cannulation pitfalls [letter] J Thorac Cardiovasc Surg. 2009;138:251. author reply 251-2.

19. Fusco DS, Shaw RK, Tranquilli M, Kopf GS, Elefteriades JA. Femoral cannulation is safe for type A dissection repair. Ann Thorac Surg. 2004;78:1285-9.

20. Gega A, Rizzo JA, Johnson MH, Tranquilli M, Farkas E, Elefteriades JA. Straight deep hypothermic arrest: experience in 394 patients supports its effectiveness as a sole means of brain preservation. Ann Thorac Surg. 2007;84:759-67.

21. Percy A, Widman S, Rizzo JA, Tranquilli M, Elefteriades JA. Deep hypothermic circulatory arrest in patients with high cognitive needs: full preservation of cognitive abilities. Ann Thorac Surg. 2009;87:117-23.

22. Ziganshin B, Elefteriades JA. Does straight DHCA suffice for brain preservation in aortic surgery? Semin Cardiothorac Surg. In press 2011.

23. Sinclair MC, Singer RL, Manley NJ, Montesano RM. Cannulation of the axillary artery for cardiopulmonary artery bypass: safeguards and pitfalls. Ann Thorac Surg. 2003;75:931-4. 